\title{
Prevalence and Predictors of Complementary and Alternative Medicine (CAM) Use Among Health Workers in Nigeria
}

\author{
Amom Tor-Anyiin $^{1}$, Rose Okonkwo ${ }^{2} \&$ Iorfa Tor-Anyiin ${ }^{3}$ \\ ${ }^{1}$ Alberta Health Services, Royal Alex Hospital Pharmacy, 10240 Kingsway, Edmonton, Canada \\ ${ }^{2}$ Principal Health Consulting Limited Benin City, Edo State, Nigeria \\ ${ }^{3}$ Department of Family Medicine, Federal Medical Center, Makurdi, Nigeria \\ Correspondence: Dr. Amom Tor-Anyiin, Alberta Health Services, Royal Alex Hospital Pharmacy, 10240 \\ Kingsway, Edmonton, AB T5H 3V9, Canada. E-mail: toranyiin@gmail.com
}

Received: October 12, 2018 Accepted: October 26, 2018 Online Published: November 5, 2018

doi:10.5539/gjhs.v10n12p40 URL: https://doi.org/10.5539/gjhs.v10n12p40

\begin{abstract}
Background: The use of complimentary and alternative medicines has risen globally. We therefore, explored the prevalence and predictors of use of complementary and alternative medicines among healthcare workers.

Methods: This was a cross-sectional study that was conducted between $1^{\text {st }}$ June and $31^{\text {st }}$ August 2018 on the use of complementary and alternative medicines among health workers in Federal Medical Center Makurdi and Benue State University Teaching Hospital, Makurdi in Benue State. Questionnaire was used to collect data from respondents and data analysed using logistic binary regression models.

Result: Response rate for the study was 80.2\% out of which females were $196(58.2 \%)$ with $215(65.7 \%)$ in the age bracket of $31-60$ years. Married respondents were 244 (72.4\%) while Medical Doctors followed by Nurses were $87(25.8 \%)$ and $84(24.9 \%)$ respectively. Majority of the respondents, $113(33.8 \%)$ have a monthly salary of above N100,000 (277.8 USD @ exchange rate of N360) while health workers of Tiv ethnic extraction had the highest number of $202(60.7 \%)$ followed by those of Idoma extraction, $95(28.5 \%)$. Those with years of work experience between $(0-15)$ were $268(87.9 \%)$. The most used CAM was spiritual therapy, $230(68.2 \%)$ while whole-body therapy was the least with $84(24.9 \%)$. Use of biological therapy and manipulative therapy were 182 (54\%) and 207 (61.4\%) respectively. The odds of a female health worker using spiritual therapy was more than twice that of their male counterpart, (AOR: $2.218,95 \%$ CI: $1.391-3.538$ ). The odds of a Community Health Extension Worker and a medical doctor using a biological therapy among the study population were four times and almost thrice respectively compared to a pharmacist (AOR: 4.117, 95\% CI: $1.690-10.030$ ) and (AOR: $2.541,95 \%$ CI: 1.095 - 5.896). The odds of an Idoma health worker using a manipulative and body-based therapy was thrice that of a Tiv health worker (AOR: $3.00,95 \%$ CI: $1.318-6.829$ ). While the odds of a Tiv health worker using whole-body therapy was seven times that of Idoma (AOR: 7.420, 95\% CI: $2.186-25.188$.
\end{abstract}

Conclusion: There was high prevalence of CAM use by health workers and this has potentials to influence integration of CAM with conventional medicines.

Keywords: alternative, complementary, health, workers, medicines

\section{Introduction}

Complementary and alternative medicine (CAM) is a term that refers to products and medicines outside conventional medical practice (Anbari \& Gholami, 2015). While there seems to be no consensus on the definition of CAM, according to the National Centre for Complementary and Alternative Medicine (NCCAM), CAM is defined as "a group of various medical and health care systems, practices, and products that are not presently considered to be an aspect of conventional medicine" (Onyiapat, Okoronkwo, \& Ogbonnaya, 2011). The use of these products and practice come in different forms and shapes. Some of the medicines come in pharmaceutical forms such as capsules, teas, concentrated extracts, decoctions, tablets, and tinctures while the practice among others include chiropractic, traditional healing, naturopathy, massage, yoga, reflexology, Ayurveda, and acupuncture (Fakeye, Adisa, \& Musa, 2009). Complementary and alternative medicines are used for various reasons as some use it as prophylactic measures while others to treat illness. 
The use of CAM has continued to rise globally in the last few decades and different reasons have been proffered for the increasing popularity of these medicines and practice both in developing and developed economies. In the USA, $89 \%$ of the population is said to use complementary medicines while a survey in two major cities in Canada (Edmonton and Ottawa) shows that the use of complementary medicines ranged from $51 \%$ to $89 \%$ (Ellison Richmond, Denise Adams, Simon Dagenais \& Lola Baydala, W James King, 2014). In the UK, prevalence of use of CAM by patients and consumers was found to be relatively lower, $51.8 \%$ (Posadzki, Watson, Alotaibi, \& Ernst, 2013). World-wide, the use of CAM varies in literature from $6 \%$ to $84 \%$ (Metcalfe, Williams, McChesney, Patten, \& Jetté, 2010). A global systematic review of 49 surveys from 15 countries for 12 -month prevalence shows a range of $9.8-76 \%$ (Harris, Cooper, Relton, Thomas, \& Harris, 2012). The range of prevalence shows an increase over what was found in the literature ten years earlier where the global prevalence of use of CAM was found to be in the range of $9 \%-65 \%$ (Ernst, 2000). In developing nations, the percentage of people that depends on CAM for their primary health care ranged from $40 \%$ in Colombia to $90 \%$ in Ethiopia (Van Andel \& Carvalheiro, 2013).

A literature review of published research work globally showed a life time use of CAM to be $30 \%-70 \%$ among people living with HIV /AIDS (PLWHA) (Lorenc \& Robinson, 2013). In a descriptive cross-sectional study of PLWHA attendees in a public hospital in Trinidad, San Fernando General Hospital, a third of the participants, 113 (32.8\%) out of 343 used one form of CAM or the other (Bahall, 2017). In the United States, a total of 53.6\% of those with severe depression reported using complementary and alternative therapies to treat their condition during the past 12 months in a survey carried out between November 1997 and February 1998 (Kessler et al., 2001). In Switzerland, prevalence of $53 \%$ was found among under 18 years who were registered at Swiss Childhood Cancer Registry (SCCR) between January 2002 and December 2011 (Magi, Kuehni, Torchetti, Wengenroth, \& Lüer, 2015). The use of CAM is also found among hypertensive patients. In a study in Baghdad, Iraq among hypertensive patients attending two public general hospitals, $65.5 \%$ (262) out of 400 , was found to have used CAM at some point concurrently with orthodox medicines (Rifaat, Azmi, Saleem, Al, \& Thanoon, 2018). The use of CAM is not exempted in pregnancy as many studies found the use of herbs and other forms of CAM among pregnant women. In Ethiopia, 48.6\% (177) participating pregnant women were found to have used CAM in their current pregnancy as at the time of the study (Mekuria, Erku, Gebresillassie, \& Birru, 2017). In northern Uganda, the prevalence compared to the study in Ethiopia was less as only $20 \%$ (78/383) was found to have used CAM during their current pregnancy (Nyeko, Tumwesigye, \& Halage, 2016).

In Nigeria, the use of CAM has been studied by various researchers. Among patients attending hematologic clinic in Lagos University Teaching Hospital, $88.5 \%$ (200) of the respondents were found to have used CAM in the preceding three months (Busari \& Mufutau, 2017). In a cross-sectional survey of three local government areas of Enugu urban in Enugu state, $84.7 \%$ (620) of respondents acknowledged use of CAM at some point in their life (Onyiapat et al., 2011). Oreagba, Oshikoya, and Amachree, (2011), found a prevalence of 66.8\% (259) for the use of herbs and other forms of CAM among residents in south - western part of Nigeria. The use of CAM is said to cut across all ages and categories of persons including healthy and those suffering from illness. Socio-economic spectrum is also not a barrier when it comes to the use of CAM. Among pregnant women from three geopolitical zones in Nigeria, prevalence of use of CAM was 67.5\% (595) (Fakeye et al., 2009).

There are many reasons why people use complementary and alternative medicines in Nigeria. For some, once it has the approved mark by the regulatory agency, National Agency for Food, Drug Administration and Control (NAFDAC), the drug is safe. For some, it has to do with affordability and availability while for others, it is for a singular fact that the product is imported. With the continued rise in the use of CAM globally, understanding the prevalence and determinants among health workers is important after all, health workers largely influence patients preference to treatment (Masanja, Lutambi, \& Khatib, 2012). Because of dearth of empirical evidence of the use of CAM among health workers in Benue State, Nigeria, the study aims to look at the prevalence and determinants of use of CAM among health workers in Makurdi, the capital city of the state. Specifically, the aim is to explore beliefs, attitude and knowledge of health workers on CAM vis-à-vis their socio-economic status. We therefore, seek to explore demographic socio-economic factors that predict the use of CAM among health workers.

\section{Materials and Methods}

This was a cross-sectional survey of health workers using questionnaires as the instrument to obtain data from the participants in Benue State in the two tertiary health institutions in the state. The health facilities included Federal Medical Center Makurdi and the Benue State University Teaching Hospital and they were purposely selected because of the size of their health workers. These two hospitals are the biggest and by our estimation, their health workers constitute over $70 \%$ of the entire health workforce of Benue State. Ethical approval for the study was obtained from the Benue State Ministry of Health and Human Services. Consent was inferred by response to the 
questionnaire. The study was restricted to only participants who could read and write. Since it will not be economically and logistically possible for us to survey the entire health workers in Makurdi, we made use of the Leslie and Kish formula (Eng, 2003) to estimate the required sample size,

$$
n=\frac{Z^{2} p q}{\delta^{2}}
$$

where $n$ equals the sample size required, $Z=$ Standard deviation set at 1.96 (Confidence Interval of 95\%). The abbreviation $p$ marks the proportions $(40 \%)$ of the attribute in the population under investigation (Van Andel \& Carvalheiro, 2013). Delta $(\delta)$ equals the marginal error $(5 \%)$; that is the level of precision taken. $\mathrm{Q}=1-p$. The estimated sample size was 369 .

Data was collected strictly with the use of questionnaire which was developed by the researchers. Data for the study was collected between $1^{\text {st }}$ June and $31^{\text {st }}$ August 2018. The questionnaire was piloted on 10 health workers who were excluded from the study and found to be easy to self-administer and took an average of only six minutes to complete. Revision was made based on comments from the pilot test. Two of the authors in addition to three research assistants were trained to facilitate the administration of the questionnaire and because the target audience was a literate population, there was no need for interpretation of the questionnaire. There were 12 questions on the questionnaire divided into two sections. The first section collected socio-demographic data which included sex, age, religion, ethnicity, marital status, occupation, income and years of professional work experience. Benue State is made of three main ethnic groups (Tiv, Idoma and Igede), any other ethnic group was grouped as 'others' in our study. The second section elicited responses on life time use of CAM which was sub-divided into biological agents, manipulation of body-based therapies, spiritual-based therapies, and whole-body medicines. All the questions contained in the questionnaire except two were close-ended with options for participants to make a choice. The open-ended questions were on age and years of work experience. Biological agents in the study included in the questionnaire were herbal medicines, honey, herbal multivitamins, food supplements and other animal products. Manipulative and body-based therapies included exercise, massage, relaxation and yoga. On the other hand, spiritual based therapies included use of holy water, anointed oils, prayers, fasting and abstinence and mantles. While whole body medicines included acupuncture, chiropractic, spinal manipulation, use of smart phones or computers among others. The data from the questionnaire were extracted into Microsoft Excel, cleaned and exported to Statistical Package for Social Sciences (IBM SPPS Inc., Chicago, IL) version 24.0. A univariate analysis was carried out and variables that showed significant association with use of CAM after Chi square test were entered into a stepwise backward logistic regression model and analysed to identify predictors of use of CAM. Statistically significant level, $\mathrm{p}$ was set at .05 .

\section{Results}

A total of 420 questionnaires were sent out to the two tertiary health institutions namely the Benue State University Teaching Hospital Makurdi and the Federal Medical Centre Makurdi. Out of the 358 questionnaires that were returned, 21 were observed to have been filled wrongly. These wrongly filled forms included those returned forms with more than an ethnic group circled, those with more than one salary band circled and those that circled both gender. Because these errors were done randomly, those questionnaires were discarded representing a return rate of $80.2 \%$. There were $196(58.2 \%)$ females while those in the age category of $31-60$ years were $215(65.7 \%)$. Among the respondents, health workers of Tiv ethnicity were 202 (60.7\%). Married respondents were 244 (72.4\%) while Medical Doctors followed by Nurses were 87 (25.8\%) and 84 (24.9\%) respectively. Majority of the respondents, $113(33.8 \%)$ had a monthly salary of above N100,000 (277.8 USD exchange rate of N360). Those with years of work experience between $(0-15)$ were 268 (87.9\%). See Table 1 for details. The most used CAM was spiritual therapy, $230(68.2 \%)$ while whole-body therapy was the least with 84 (24.9\%). Use of biological therapy and manipulative therapy were $182(54 \%)$ and $207(61.4 \%)$ respectively. See Figure 1 for details. The population was a homogenous one with respect to religion as $337(100 \%)$ indicated Christianity as their religion. Religion was therefore excluded from the analysis. 
Table 1. Socio-demographic variables

\begin{tabular}{|c|c|c|}
\hline Variable & $\mathrm{N}$ & $\%$ \\
\hline Sex & 337 & \\
\hline Female & 196 & 58.2 \\
\hline Male & 141 & 41.8 \\
\hline Age (Years) & 327 & \\
\hline $16-30$ & 104 & 31.8 \\
\hline $31-60$ & 215 & 65.7 \\
\hline Above 60 & 8 & 2.4 \\
\hline Religion & 334 & \\
\hline Christianity & 334 & 100.0 \\
\hline Ethnicity & 333 & \\
\hline Idoma & 95 & 28.5 \\
\hline Igede & 23 & 6.9 \\
\hline Others & 13 & 3.9 \\
\hline Tiv & 202 & 60.7 \\
\hline Marital Status & 337 & \\
\hline Married & 244 & 72.4 \\
\hline Single, separated, or divorced & 86 & 25.5 \\
\hline Widowed & 7 & 2.1 \\
\hline Occupation & 337 & \\
\hline CHEW/SCHEW & 62 & 18.4 \\
\hline Lab Scientist & 10 & 3.0 \\
\hline Medical Doctor & 87 & 25.8 \\
\hline Nurse & 84 & 24.9 \\
\hline Others & 58 & 17.2 \\
\hline Pharmacist & 36 & 10.7 \\
\hline Income (Naira) & 334 & \\
\hline $0-40,000$ & 82 & 24.6 \\
\hline $41,000-100,000$ & 139 & 41.6 \\
\hline Above 100,000 & 113 & 33.8 \\
\hline Years of Work Experience & 305 & \\
\hline $0-15$ & 268 & 87.9 \\
\hline $16-30$ & 30 & 9.8 \\
\hline $31-45$ & 7 & 2.3 \\
\hline
\end{tabular}




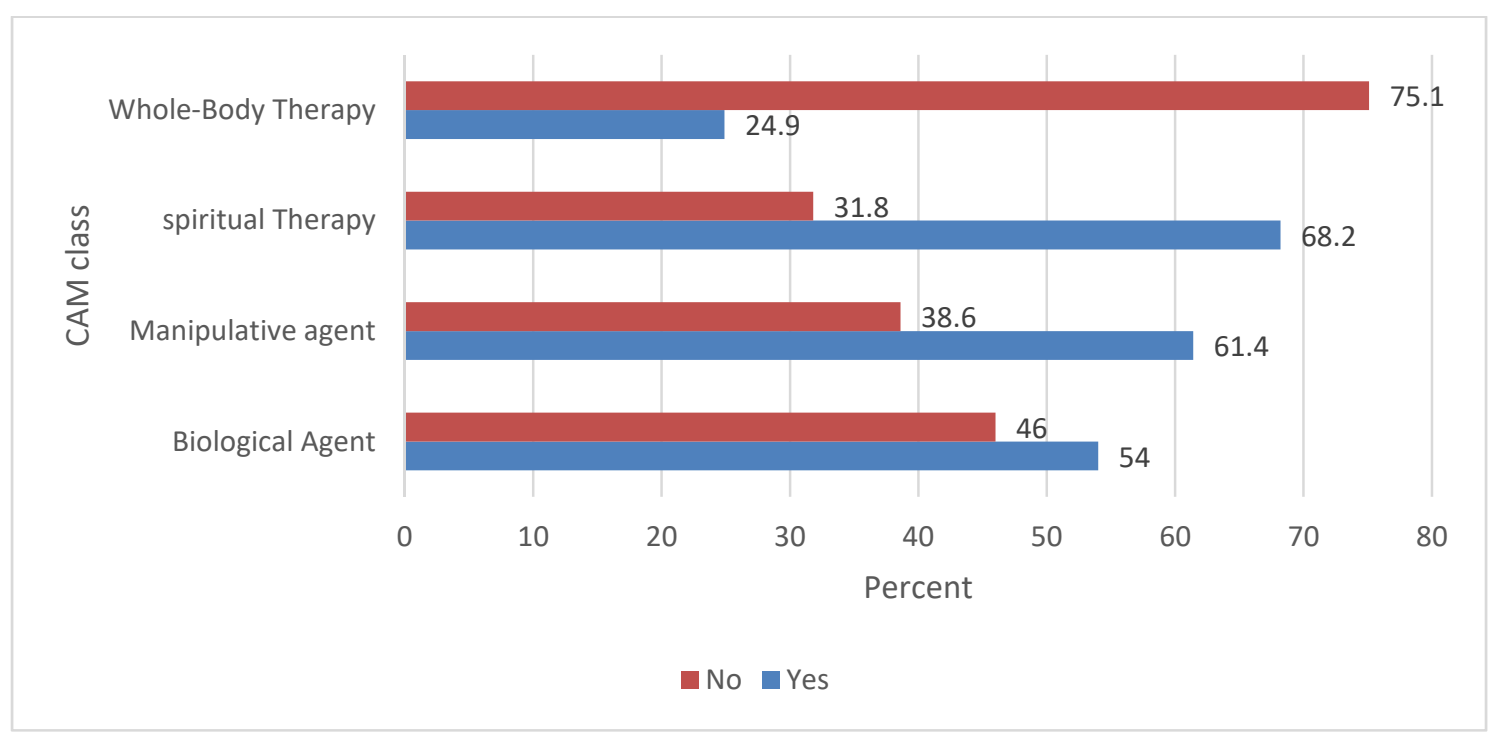

Figure 1. Chart showing percentage of respondents using CAM

\subsection{Biological Agents}

Among the ethnic groups, the odds of 'others' using a biological agent was almost 11 times compared to a Tiv health worker (AOR: $10.87,95 \%$ CI: 1.387 - 85.150) while the odds of an Igede health worker taking a biological agent decreased by $68 \%$ compared to a Tiv health worker (AOR: $0.320,95 \%$ CI: $0.121-0.844$ ). The odds of a Health Extension Worker taking biological agent was four times compared to a Pharmacist (AOR: 4.11, 95\% CI:1.690 -10.030) while that of a Medical Doctor was twice that of a Pharmacist (AOR: 2.54, 95\% CI: 1.095 5.896). The odds of someone with an income between N41,000 - N100,000 (114 USD - 278 USD) consuming a biological agent decreased approximately $70 \%$ compared to those with an income greater than N100,000 (>278 USD) (AOR: 0.294, 95\% CI: $0.174-0.496$ ). Lit review. (See Table 2)

Table 2. Use of biological agents by responders

\begin{tabular}{|c|c|c|c|c|c|}
\hline Variable & $\mathrm{n}$ & $\begin{array}{l}\text { Non-Users of } \\
\text { CAM \% }\end{array}$ & $\begin{array}{l}\text { Users of } \\
\text { CAM \% }\end{array}$ & Adjusted OR $(95 \% \mathrm{CI})$ & P value \\
\hline \multicolumn{6}{|l|}{ Ethnicity } \\
\hline Idoma & 95 & 43.2 & 56.8 & $1.193(.730-1.949)$ & .482 \\
\hline Igede & 23 & 73.9 & 26.1 & $.320(0.121-.844)$ & .021 \\
\hline Others & 13 & 7.7 & 92.3 & $10.868(1.387-85.150)$ & .023 \\
\hline Tiv & 202 & 47.5 & 52.5 & 1 & \\
\hline \multicolumn{6}{|l|}{ Marital Status } \\
\hline Married & 244 & 38.9 & 61.1 & $2.091(.458-9.551)$ & .341 \\
\hline Separated, divorced, or single & 86 & 65.1 & 34.9 & $.714(0.150-3.403)$ & .673 \\
\hline Widowed & 7 & 57.1 & 42.9 & 1 & \\
\hline \multicolumn{6}{|l|}{ Occupation } \\
\hline CHEW/SCHEW & 62 & 38.7 & 61.3 & $4.117(1.690-10.030)$ & .002 \\
\hline Lab Scientist & 10 & 70 & 30 & $1.114(.240-5.180)$ & .890 \\
\hline Medical Doctor & 87 & 50.6 & 49.4 & $2.541(1.095-5.896)$ & .030 \\
\hline Nurse & 84 & 53.6 & 46.4 & $2.253(.967-5.251)$ & .060 \\
\hline Others & 58 & 15.5 & 84.5 & $14.156(5.113-39.193)$ & .001 \\
\hline Pharmacist & 36 & 72.2 & 27.8 & 1 & \\
\hline
\end{tabular}


Monthly Income (N)

$0-40,000$

$82 \quad 43.9$

56.1

$.573(.318-1.035)$

.065

41, $0000-100,000$

139

60.4

39.6

$.294(.174-.496)$

.001

$>100,000$

$113 \quad 31$

69

1

\subsection{Manipulative Therapies}

The odds of an Idoma health worker using a manipulative agent was thrice that of a Tiv health worker (AOR: 3.00, 95\% CI: 1.318 -6.829). The odds of a Health Extension Worker, a Medical Doctor and a Nurse using a manipulative agent were about 11 times (AOR: 10.936, 95\% CI: 2.135-56.009), five times (AOR: 5.269, 95\% CI: $1.847-15.035$ ) and about four times (AOR: 3.95, 95\% CI: $1.268-12.092$ ) respectively compared to that of a Pharmacist. See Table 3 for details.

Table 3. Use of manipulative therapies

\begin{tabular}{|c|c|c|c|c|c|c|}
\hline Variable & $\mathrm{n}$ & $\begin{array}{l}\text { Non-Users } \\
\text { CAM \% }\end{array}$ & of & $\begin{array}{l}\text { Users of } \\
\text { CAM \% }\end{array}$ & Adj OR $(95 \% \mathrm{CI})$ & $\begin{array}{l}\mathrm{P} \\
\text { value }\end{array}$ \\
\hline \multicolumn{7}{|l|}{ Ethnicity } \\
\hline Idoma & 95 & 26.3 & & 73.7 & $3.00(1.318-6.829)$ & .009 \\
\hline Igede & 23 & 39.1 & & 60.9 & $1.026(.0 .244-4.315)$ & 0.927 \\
\hline Others & 13 & 7.7 & & 92.3 & $4.772(0.198-115.003)$ & 0.336 \\
\hline Tiv & 202 & 47 & & 53 & 1 & \\
\hline \multicolumn{7}{|l|}{ Occupation } \\
\hline CHEW/SCHEW & 62 & 38.7 & & 61.3 & $10.936(2.135-56.009)$ & .004 \\
\hline Lab Scientist & 10 & 70 & & 30 & $0.694(0.113-4.275)$ & 0.694 \\
\hline Medical Doctor & 87 & 34.5 & & 65.5 & $5.269(1.847-15.035)$ & 0.002 \\
\hline Nurse & 84 & 38.1 & & 61.9 & $3.915(1.268-12.092)$ & 0.018 \\
\hline Others & 58 & 24.1 & & 75.9 & $9.316(2.653-32.713)$ & 0.001 \\
\hline Pharmacist & 36 & 63.9 & & 36.1 & 1 & \\
\hline \multicolumn{7}{|c|}{ Monthly Income (N) } \\
\hline $0-40,000$ & 82 & 43.9 & & 56.1 & $0.347(0.099-1.223)$ & 0.100 \\
\hline $41,000-100,000$ & 139 & 46.8 & & 53.2 & $0.560(0.263-1.189)$ & 0.131 \\
\hline$>100,000$ & 113 & 25.7 & & 74.3 & 1 & \\
\hline
\end{tabular}

\subsection{Spiritual Therapy}

The odds of a female health worker using a spiritual therapy was twice that of a male (AOR: $2.218,95 \%$ CI: 1.391 - 3.538). The odds of a Nurse using a spiritual therapy was four times that of a Health Extension Worker (AOR: 4.191, 95\% CI: 1.857 - 9.462) while the odds of a Pharmacist being among spiritual therapy users decreased by $82 \%$ compared to a Health Extension Worker (AOR: 0.180, 95\% CI: $0.071-0.461$ ). Compared to those with an income of N40,000 and below ( $\leq 111$ USD) the odds of a health worker that received over N100,000 (>278 USD) using a spiritual therapy decreased by $72 \%$ (AOR: $0.283,95 \%$ CI: $0.159-0.506$ ). See Table 4. 
Table 4. Use of spiritual therapy

\begin{tabular}{|c|c|c|c|c|c|}
\hline Variable & $\mathbf{n}$ & $\begin{array}{l}\text { Non-Users of } \\
\text { CAM \% }\end{array}$ & $\begin{array}{l}\text { Users of } \\
\text { CAM \% }\end{array}$ & Adj OR (95\% CI) & P value \\
\hline \multicolumn{6}{|l|}{ Sex } \\
\hline Female & 196 & 24.5 & 75.5 & $2.218(1.391-3.538)$ & 0.001 \\
\hline Male & 141 & 41.8 & 58.2 & 1 & \\
\hline \multicolumn{6}{|l|}{ Occupation } \\
\hline Lab Scientist & 10 & 40 & 60 & $0.947(0.242-3.708)$ & 0.938 \\
\hline Medical Doctor & 87 & 31 & 69 & $1.404(0.708-2.781)$ & 0.331 \\
\hline Nurse & 84 & 13.1 & 86.9 & $4.191(1.857-9.462)$ & 0.001 \\
\hline Others & 58 & 22.4 & 77.6 & $2.189(0.981-4.872)$ & 0.056 \\
\hline Pharmacist & 36 & 77.8 & 22.2 & $0.180(0.071-0.461)$ & 0.001 \\
\hline CHEW/SCHEW & 62 & 38.7 & 61.3 & 1 & \\
\hline \multicolumn{6}{|l|}{ Monthly Income (N) } \\
\hline$>100,000$ & 113 & 18.6 & 81.4 & $0.283(0.159-0.506)$ & 0.001 \\
\hline $41,0000-100,000$ & 139 & 44.6 & 55.4 & $0.552(0.282-1.080)$ & 0.083 \\
\hline $0-40,000$ & 82 & 29.3 & 70.7 & 1 & \\
\hline
\end{tabular}

\subsection{Whole-Body Therapies}

It was only marital status that showed no significant association with use of whole-body therapies after using Chi-square. The remaining variables that showed a significant association were included in the binary logistics regression. The odds of a female health worker using a whole-body therapy was thrice that of a male (AOR: 3.186 , $95 \%$ CI: $1.816-5.620$ ). The odds of a those between ages $31-60$ years using a whole-body therapy was $83 \%$ less compared to those who were above 60 years (AOR: $0.283,95 \%$ CI: $0.159-0.506$ ). The odds of a Tiv health worker using a whole-body therapy was seven times that of an Idoma health worker (AOR: 7.420, 95\% CI: 2.186 - 25.188). As for the laboratory scientists, their odds of using a whole-body therapy was 14 times that of a Pharmacist (AOR: 14.733, 95\% CI: 1.942 - 111.782) and lastly, the odds of a health worker with maximum of 15 years using a whole-body therapy was reduced by $82 \%$ compared to those with over 30 years of work experience (AOR: $0.176,95 \%$ CI: $0.038-0.812$ ). See Table 5.

Table 5. Use of whole-body therapy

\begin{tabular}{llllll}
\hline Variable & $\mathrm{N}$ & Non-Users of CAM \% & Users of CAM \% & Adj OR $(95 \%$ CI $)$ & P value \\
\hline Sex & 196 & 66.8 & & & \\
Female & 141 & 86.5 & 33.2 & $3.186(1.816-5.620)$ & 0.001 \\
Male & & & 13.5 & 1 & \\
\hline Age & 104 & 53.8 & & & \\
$16-30$ & 215 & 85.6 & 46.2 & $0.857(0.203-3.612)$ & 0.834 \\
$31-60$ & 8 & 50 & 14.4 & $0.168(0.040-0.709)$ & 0.0151 \\
61 and above & & & 50 & 1 & \\
\hline Ethnicity & 23 & 87 & & & 0.568 \\
Igede & 13 & 30.8 & 13 & $0.495(0.141-1.738)$ & 0.272 \\
Others & 202 & 76.7 & 69.2 & $7.420(2.186-25.188)$ & 0.001 \\
Tiv & 95 & 73.7 & 23.3 & 1 & \\
Idoma & & 26.3 & & \\
\hline
\end{tabular}




\begin{tabular}{llllll}
\hline Occupation & & & & & \\
CHEW/SCHEW & 62 & 80.6 & 19.4 & $0.509(0.084-3.077)$ & 0.462 \\
Lab Scientist & 10 & 30 & 70 & $14.733(1.942-111.782)$ & 0.009 \\
Medical Doctor & 87 & 83.9 & 16.1 & $0.957(0.240-3.809)$ & 0.950 \\
Nurse & 84 & 83.3 & 16.7 & $0.659(0.140-3.101)$ & 0.598 \\
Others & 58 & 46.6 & 53.4 & $2.509(0.339-18.550)$ & 0.368 \\
Pharmacist & 36 & 83.3 & 16.7 & 1 & \\
\hline Monthly Income (N) & & & & & 0.689 \\
$0-40,000$ & 82 & 75.6 & 24.4 & $1.470(0.222-9.740)$ & 0.207 \\
$41,0000-100,000$ & 139 & 77.7 & 22.3 & $0.469(0.144-1.521)$ & \\
Greater than 100,000 & 113 & 70.8 & 29.2 & 1 & 0.026 \\
\hline Years of Work Experience & & & & $0.176(0.038-0.812)$ & 0.188 \\
$0-15$ & 268 & 81 & 19 & $0.321(0.059-1.739)$ & \\
$16-30$ & 30 & 70 & 30 & 1 & \\
$31-45$ & 7 & 42.9 & 57.1 & & \\
\hline
\end{tabular}

\section{Discussion}

There have been considerable debates whether CAM should be completely incorporated into orthodox medicine. While some consider CAM as an untapped resource base for health care services, others still have a strong doubt regarding the veracity of its efficacy relative to orthodox medicines. According to the World Health Organisation, most people in developing nations still use complementary and alternative medicines for their health care (World Health Organization, 2002). In view of the crucial role played by health workers in healthcare delivery, it is important to understand the predisposing factors and prevalence of use of CAM among them. Our study shows a high prevalence of use of CAM and this is not surprising as health workers are well exposed to CAM (Johnson, Ward, \& Knutson, 2011).

\subsection{Spiritual Therapy}

Among the four categories of CAM in the study, spiritual therapy had the highest prevalence of $220(68.2 \%)$. The use of spiritual therapy which is not new in healthcare services has continued to gain strong ground in healthcare and there are many studies that show a strong link to the use of spiritual therapy in healing and healthcare (Narayanasamy \& Narayanasamy, 2008; Puchalski, 2001). In a study by American pain Society for patients in different kinds of pains, $76 \%$ preferred personal prayer for their healing to relaxation, pain medication, massage and pain injection (Mcneill et al., 1998). Some of the components of spirituality as contained in our research questionnaire included use of anointed oil, prayer, use of holy water and of mantles. In a systematic review of studies on prayer in healthcare of patients, $57 \%(7 / 12)$ of the participants in the literature review considered prayer as a vital factor in healing (Simão, Caldeira, \& Carvalho, 2016). In our study, the odds of a female health worker using spiritual therapy was more than twice that of their male counterpart, (AOR: 2.218, 95\% CI: $1.391-3.538$ ). This finding agrees with that of a study in Australia where $26 \%$ of women used spiritual healing on regular basis and in the presence of illness such as cancer, the odds of using spiritual therapy was almost twice that of men (OR 1.84; 95\% CI 1.28 to 2.65) (Rao, Sibbritt, Phillips, \& Hickman, 2015). It is pertinent to note that females in Nigeria seek spiritual help much more than their male counterpart and topmost on the reasons for seeking such help is health problems (Balogun \& Oladipo, 2009). Based on our findings, a Nurse is four times more likely to seek spiritual help compared to a CHEW while a Pharmacist is $78 \%$ less likely to use spiritual therapy. The high likelihood of use of spiritual therapy by nurses could be related to their profession. Spirituality is known to have relevance to all aspect of nursing care and not only for patients at the point death or palliative care (Giske \& Cone, 2015). Nurses are also known to derive their strength on spirituality especially when relating with their patients (Evangelista, 2016).

\subsection{Biological Agent}

The prevalence of use of biological agents among the surveyed health workers in Benue State was 54\% (182) and this is not surprising as a related study on the subject matter showed a similar prevalence of $56 \%$ (347) and $62.9 \%$ 
(156) among adults in Eastern and South Western Nigeria respectively and (Busari \& Mufutau, 2017; Onyiapat et al., 2011). In Selangor, Malaysia, use of biological therapy among diabetic patients was found to be $50 \%$ (150) (Ching, Zakaria, Paimin, \& Jalalian, 2013). Many reasons have been provided for the popularity of biological agents as many consider them to be relatively safe, natural, less side effects, affordable and very effective (Sirois, Salamonsen, \& Kristoffersen, 2016). The high prevalence of the use of biological therapy among health workers therefore, may be connected to the belief that biological therapy is effective, natural, lesser side effects and probably more affordable. Health workers of Igede ethnic extraction were $68 \%$ less likely to use biological therapy compared to their Tiv counterpart. This is not surprising as the use of biological agents for treatment is common among the Tiv ethnic group. The use of herbs for medicinal purposes among the Tiv people has been widely documented (Adebayo \& Krettli, 2011; Tor-Anyiin, Sha'ato, \& Oluma, 2003). In our research work, the odds of a CHEW and a medical doctor using a biological therapy among the study population were four times and almost thrice respectively compared to a pharmacist (AOR: 4.117, 95\% CI: $1.690-10.030$ ) and (AOR: $2.541,95 \%$ CI: $1.095-5.896$ ). The reason for the low odds of use of biological therapy among pharmacists could be documented concerns for CAM as reported among pharmacists. As experts in the study of drugs, pharmacists are said to express concern on the use of complimentary and alternative medicines due to perceived lack of scientific evidence on the efficacy of CAM and lack of knowledge of CAM (Culverhouse \& Wohlmuth, 2012; Oi, Ung, Harnett, \& Hu, 2017). The probability of health worker that received N41000 - N100,000 per month taking a biological therapy was $70 \%$ less compared to those collecting over N100,000 monthly. This could be that the higher the income, the stronger the purchasing power.

\subsection{Manipulative and Body-based Therapy}

The prevalence of use of manipulative and body-based therapy was $61.4 \%$ (207) and from the study, the odds of a health worker of Idoma extraction using a manipulative and body-based therapy was thrice that of a Tiv health worker (AOR: $3.00,95 \% \mathrm{CI}: 1.318-6.829$ ). This is not surprising as ethnicity is associated with use of CAM among health workers (Bahall \& Legall, 2017). The odds of a CHEW using manipulative and body-based therapies was 10 times that of a Pharmacist while the odds of a Medical Doctor and Nurse were five and four times respectively compared to a Pharmacist. The high prevalence of usage of this class of CAM is not surprising as earlier studies showed a high prevalence as well. In a study among peasant farmers in south western Nigeria, $80.1 \%$ (173) was found to have used massage as a therapy (Mbada et al., 2015). The reason for the relatively low odds of use manipulative and body-based therapy by pharmacists requires further research.

\subsection{Whole-body Therapy}

From our research, the prevalence of use of whole-body therapy was the least, $24.9 \%$ (84). This to our views is not surprising as the use of acupuncture, chiropractic, spinal manipulation, smart phones and computers among others is not common in Nigeria. The odds of a female using whole-body treatment was thrice that of male (AOR: 3.186, $95 \%$ CI: $1.816-5.620$ ) and this agrees with a study on use of CAM among health workers in Trinidad and Tobago (Bahall \& Legall, 2017). Whereas, those between ages $31-60$ were $83 \%$ less likely to use whole-body compared to those who were 61 years and above. The odds of a health worker of Tiv extraction using whole-body therapy was seven times that of Idoma (AOR: 7.420, 95\% CI: 2.186-25.188. These findings agree with two cross-sectional studies in the US where females were more likely to use a whole-body therapy while those less than 44 years were less likely to use whole-body compared to older adults ( $\geq 65$ years) (Ramamonjiarivelo, Qu, \& Ellis-Griffith, 2016; Zhang, Lao, Chen, \& Ceballos, 2012). The study by Ramamonjiarivelo et al., (2016) showed that place of origin is a predisposing factor to the use of whole-body and this could explain why the odds of use of whole-body is higher for health workers of Tiv ethnic group compared to their Idoma counterpart as the geographic origin of these tribes differs.

\section{Conclusion}

To the best of our knowledge, this is the first study in Nigeria that focused on the prevalence and predictors of CAM among health workers. The high prevalence of CAM use by health workers has potentials to influence integration of CAM with conventional medicines. Further research is needed to explore attitudes, belief and knowledge on the use of CAM by health workers. While the results of the study can not be generalised to all health workers in Nigeria, findings have enriched the body of knowledge in this field.

\section{Acknowledgements}

We wish to declare that we did not receive any financial support from anyone for the study. We appreciate the three research assistants that helped in the data collection namely Jerome Anaakaa, Philip Anongo and Torkuma Tor-Anyiin. The Benue State Ministry of Health is also acknowledged for granting the ethical approval for the 
study.

\section{Competing Interests Statement}

The authors declare that there are no competing or potential conflicts of interest.

\section{References}

Adebayo, J. O., \& Krettli, A. U. (2011). Potential antimalarials from Nigerian plants: A review. Journal of Ethnopharmacology, 133(2), 289-302. https://doi.org/10.1016/j.jep.2010.11.024

Anbari, K., \& Gholami, M. (2015). Evaluation of Trends in the Use of Complementary and Alternative Medicine in Health Centers in Khorramabad (West of Iran). Global Journal of Health Science, 8(2), 72-76. https://doi.org/10.5539/gjhs.v8n2p72

Bahall, M., \& Legall, G. (2017). Knowledge, attitudes, and practices among health care providers regarding complementary and alternative medicine in Trinidad and Tobago. BMC complementary and alternative medicine, 17(1), 144. https://doi.org/10.1186/s12906-017-1654-y

Bahall, M. (2017). Prevalence, patterns, and perceived value of complementary and alternative medicine among cancer patients: a cross-sectional, descriptive study. BMC complementary and alternative medicine, 17(1), 345. https://doi.org/10.1186/s12906-017-1928-4

Balogun, S. K., \& Oladipo, S. E. (2009). What Problem do Women Seek Spiritual Help for?. Studies on Ethno-Medicine, 3(2), 145-151.

Busari, A. A., \& Mufutau, M. A. (2017). High prevalence of complementary and alternative medicine use among patients with sickle cell disease in a tertiary hospital in Lagos, South West, Nigeria. BMC Complementary and Alternative Medicine, 17(1), 1-8. https://doi.org/10.1186/s12906-017-1812-2

Ching, S. M., Zakaria, Z. A., Paimin, F., \& Jalalian, M. (2013). Complementary alternative medicine use among patients with type 2 diabetes mellitus in the primary care setting: a cross-sectional study in. $B M C$ Complementary and Alternative Medicine, 13(1), 1. https://doi.org/10.1186/1472-6882-13-148

Culverhouse, S. E., \& Wohlmuth, H. (2012). Factors affecting pharmacists ' recommendation of complementary medicines - a qualitative pilot study of Australian pharmacists. BMC Complementary and Alternative Medicine, 12(1), 1. https://doi.org/10.1186/1472-6882-12-183

Ellison Richmond, Denise Adams, Simon Dagenais, T. C., \& Lola Baydala, W James King, S. V. (2014). Complementary and alternative medicine: a survey of its use in pediatric cardiology. CMAJ Open, 2(4), E217-E224. https://doi.org/10.9778/cmajo.20130075

Eng, J. (2003). Sample size estimation: how many individuals should be studied?. Radiology, 227(2), 309-313.

Ernst, E. (2000). Prevalence of use of complementary/alternative medicine: a systematic review. Bulletin of the world health organization, 78, 258-266.

Evangelista, C. B., Lopes, M. E. L., Costa, S. F. G. D., Abrão, F. M. D. S., Batista, P. S. D. S., \& Oliveira, R. C. D. (2016). Spirituality in patient care under palliative care: A study with nurses. Escola Anna Nery, 20(1), 176-182. https://doi.org/10.5935/1414-8145.20160023

Fakeye, T. O., Adisa, R., \& Musa, I. E. (2009). Attitude and use of herbal medicines among pregnant women in Nigeria. BMC Complementary and Alternative Medicine, 9, 1-7. https://doi.org/10.1186/1472-6882-9-53

Giske, T., \& Cone, P. H. (2015). Discerning the healing path-how nurses assist patient spirituality in diverse health care settings. Journal of clinical nursing, 24(19-20), 2926-2935. https://doi.org/10.1111/jocn.12907

Harris, P. E., Cooper, K. L., Relton, C., \& Thomas, K. J. (2012). Prevalence of complementary and alternative medicine (CAM) use by the general population: a systematic review and update. International journal of clinical practice, 66(10), 924-939. https://doi.org/10.1111/j.1742-1241.2012.02945.x

Johnson, P. J., Ward, A., Knutson, L., \& Sendelbach, S. (2012). Personal use of complementary and alternative medicine (CAM) by US health care workers. Health services research, 47(1pt1), 211-227. https://doi.org/10.1111/j.1475-6773.2011.01304.x

Lorenc, A., \& Robinson, N. (2013). A review of the use of complementary and alternative medicine and HIV: issues for patient care. AIDS patient care and STDs, 27(9), 503-510. https://doi.org/10.1089/apc.2013.0175

Magi, T., Kuehni, C. E., Torchetti, L., Wengenroth, L., Lüer, S., \& Frei-Erb, M. (2015). Use of complementary and alternative medicine in children with cancer: A study at a Swiss university hospital. PloS one, 10(12), 
e0145787. https://doi.org/10.1371/journal.pone.0145787

Masanja, I. M., Lutambi, A. M., \& Khatib, R. A. (2012). Do health workers ' preferences influence their practices ? Assessment of providers ' attitude and personal use of new treatment recommendations for management of uncomplicated malaria, Tanzania. BMC Public Health, 12(1), 1. https://doi.org/10.1186/1471-2458-12-956

Mbada, C. E., Adeyemi, T. L., Adedoyin, R. A., Badmus, H. D., Awotidebe, T. O., Arije, O. O., \& Omotosho, O. S. (2015). Prevalence and modes of complementary and alternative medicine use among peasant farmers with musculoskeletal pain in a rural community in South-Western Nigeria. BMC complementary and alternative medicine, 15(1), 164. https://doi.org/10.1186/s12906-015-0695-3

McNeill, J. A., Sherwood, G. D., Starck, P. L., \& Thompson, C. J. (1998). Assessing clinical outcomes: patient satisfaction with pain management. Journal of pain and symptom management, 16(1), 29-40.

Mekuria, A. B., Erku, D. A., Gebresillassie, B. M., Birru, E. M., Tizazu, B., \& Ahmedin, A. (2017). Prevalence and associated factors of herbal medicine use among pregnant women on antenatal care follow-up at University of Gondar referral and teaching hospital, Ethiopia: a cross-sectional study. BMC complementary and alternative medicine, 17(1), 86. https://doi.org/10.1186/s12906-017-1608-4

Metcalfe, A., Williams, J., McChesney, J., Patten, S. B., \& Jetté, N. (2010). Use of complementary and alternative medicine by those with a chronic disease and the general population -- results of a national population based survey. BMC Complementary \& Alternative Medicine, 10, 6p-6p. https://doi.org/10.1186/1472-6882-10-58

Narayanasamy, A., \& Narayanasamy, M. (2008). The healing power of prayer and its implications for nursing. British Journal of Nursing, 17(242-244).

Nyeko, R., Tumwesigye, N. M., \& Halage, A. A. (2016). Prevalence and factors associated with use of herbal medicines during pregnancy among women attending postnatal clinics in Gulu district, Northern Uganda. BMC Pregnancy and Childbirth, 1-12. https://doi.org/10.1186/s12884-016-1095-5

Ung, C. O. L., Harnett, J., \& Hu, H. (2017). Key stakeholder perspectives on the barriers and solutions to pharmacy practice towards complementary medicines: an Australian experience. BMC complementary and alternative medicine, 17(1), 394. https://doi.org/10.1186/s12906-017-1899-5

Onyiapat, J. E., Okoronkwo, I. L., \& Ogbonnaya, N. P. (2011). Complementary and alternative medicine use among adults in Enugu, Nigeria. BMC Complementary and Alternative Medicine, 11(1), 19. https://doi.org/10.1186/1472-6882-11-19

Oreagba, I. A., Oshikoya, K. A., \& Amachree, M. (2011). Herbal medicine use among urban residents in Lagos , Nigeria. BMC Complementary and Alternative Medicine, $11(1), \quad 117$. https://doi.org/10.1186/1472-6882-11-117

Posadzki, P., Watson, L. K., Alotaibi, A., \& Ernst, E. (2013). Prevalence of use of complementary and alternative medicine (CAM) by patients/consumers in the UK: systematic review of surveys. Clinical Medicine, 13(2), 126-131.

Puchalski, C. (2001). The role of spirituality in health care. Baylor University Medical Center Proceeding, 14(4), 352-357.

Ramamonjiarivelo, Z. H., Qu, H., \& Ellis-Griffith, G. (2016). Acupuncture Use in the United States: Who, Where, Why, and at What Price? Health Marketing Quarterly, 32(2), 113-128,.

Posadzki, P., Watson, L. K., Alotaibi, A., \& Ernst, E. (2013). Prevalence of use of complementary and alternative medicine (CAM) by patients/consumers in the UK: systematic review of surveys. Clinical Medicine, 13(2), 126-131. https://doi.org/10.1136/bmjopen-2014-007345

Ibrahim, I. R., Hassali, M. A., Saleem, F., Al Tukmagi, H. F., \& Dawood, O. T. (2018). Use of complementary and alternative medicines: a cross-sectional study among hypertensive patients in Iraq. Journal of Pharmaceutical Health Services Research, 9(1), 59-65. https://doi.org/10.1111/jphs.12209

Simão, T. P., Caldeira, S., \& de Carvalho, E. C. (2016). The effect of prayer on patients' health: systematic literature review. Religions, 7(1), 11. https://doi.org/10.3390/rel7010011

Sirois, F. M., Salamonsen, A., \& Kristoffersen, A. E. (2016). Reasons for continuing use of Complementary and Alternative Medicine (CAM ) in students: A consumer commitment model. BMC Complementary and Alternative Medicine, 1-9. https://doi.org/10.1186/s12906-016-1059-3

Tor-Anyiiin, T., Sha'ato, R., \& Oluma, H. O. (2003). Ethnobotanical Survey of Anti-Malarial Medicinal Plants 
Amongst the Tiv People of Nigeria. Journal of Herbs, Spices \& Medicinal Plants, 10(3), 61-74.

Van Andel, T., \& Carvalheiro, L. G. (2013). Why urban citizens in developing countries use traditional medicines: The case of suriname. Evidence-Based Complementary and Alternative Medicine, 2013. https://doi.org/10.1155/2013/687197

World Health Organization. (2002). WHO launches the first global strategy on traditional and alternative medicine. Retrieved from http://www.who.int/inf/en/pr-2002-38.html.

Zhang, Y., Lao, L., Chen, H., \& Ceballos, R. (2012). Acupuncture use among american adults: what acupuncture practitioners can learn from national health interview survey 2007?. Evidence-Based Complementary and Alternative Medicine, 2012. https://doi.org/10.1155/2012/710750

\section{Copyrights}

Copyright for this article is retained by the author(s), with first publication rights granted to the journal.

This is an open-access article distributed under the terms and conditions of the Creative Commons Attribution license (http://creativecommons.org/licenses/by/4.0/). 